\title{
Distribution of p53 binding protein 1 (53BP1) and phosphorylated H2A.X during mouse preimplantation development in the absence of DNA damage
}

\author{
CÉLINE ZIEGLER-BIRLING, ANNE HELMRICH, LÀSZLÒ TORA and MARIA-ELENA TORRES-PADILLA* \\ Institut de Génétique et de Biologie Moléculaire et Cellulaire (IGBMC), CNRS/INSERM U964, Université de Strasbourg, France
}

\begin{abstract}
The cells in the preimplantation mammalian embryo undergo several rounds of fast cell division. Whether the known DNA repair pathways are active during these early stages of development where cell division is of primary importance, has not been fully established. Because of the important role of phosphorylated H2A.X ( $\gamma \mathrm{H} 2 \mathrm{~A} . \mathrm{X})$ in the DNA damage response as well as its putative role in assembly of embryonic chromatin, we analysed its distribution in the preimplantation mouse embryo. We found that H2A.X is highly phosphorylated throughout preimplantation development in the absence of any induced DNA damage. Moreover, $\gamma H 2 A . X$ levels vary significantly throughout the cell cycle. Interestingly, after the 4-cell stage, we detected high levels of H2A.X phosphorylation in mitosis, where telomeres appeared focally enriched with $\gamma$ H2A.X. In contrast, 53BP1, which is known to be recruited to DNA damage sites, is undetectable at mitotic chromosomes at these stages and its localisation changes upon blastocyst formation from mainly nuclear to cytoplasmic. We also show that 53BP1 and $\gamma \mathrm{H} 2 \mathrm{~A}$.X rarely colocalise, suggesting that the high levels of phosphorylation of H2A.X in the embryo might not be directly linked to the DNA damage response in the embryo. Our data suggest that phosphorylation of H2A.X is an important event in the fast dividing cells of the early embryo in the absence of any induced DNA damage. We discuss the possible consequences of these findings on the genomewide chromatin remodelling that ocurs in the preimplantation mammalian embryo.
\end{abstract}

KEY WORDS: phospho H2A.X, mouse embryo, histone phosphorylation, chromatin

\section{Introduction}

The DNA is daily exposed to a variety of agents that can potentially cause damage. Amongst these, double strand breaks (DSB) occur in response to a variety of environmental stresses such as ionizing radiation (Ismail and Hendzel, 2008). Cellular response to DSBs involves key proteins that function by delaying cell cycle thereby allowing repair of DNA damage. Cell cycle checkpoints become activated upon DNA damage and are essential to allow proper progression through the cell cycle and safeguard the integrity of the genetic information (Fernandez-Capetillo et al., 2003a, Stiff et al., 2004, Wang et al., 2002). Responses to the DNA damage are therefore essential to ensure the transmission of intact genetic information. The cells in the preimplantation mammalian embryo proliferate with a high rate compared to somatic, differentiated cells and spend most of their cell cycle in the $S$ and G2-phases. In particular, the $G 1$ phase of the blastomeres is short or almost non-existing. The mammalian embryo develops within the reproductive tract of the female, in a relatively protected environment within the uterus. The response to different DNA-damaging agents or whether the known DNA repair pathways are active during these stages of development where cell division is central, has not been fully established. This knowledge will help us to further understand early and key steps of embryonic development.

Abbreviations used in this paper: 53BP1, p53 binding protein 1; DAPI, 4'-6diamidino-2-phenylindole; DSB, double strand breaks; PN0-5, pronuclear Stage 0 to 5; TRF1, telomere repeat binding factor 1 .

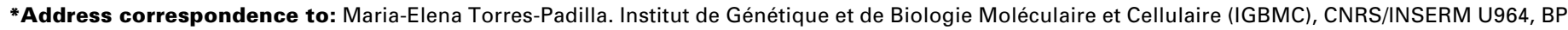
10142, F-67404 IllkirchCedex, CU de Strasbourg, France. Tel. +33(0)-3-8865-3360. Fax. + 33(0)-3-8865-3201. e-mail: metp@igbmc.fr web: http://igbmc.fr/Torres-Padilla
}

Accepted: 15 January 2009. Published online: 12 June 2009. 
Eukaryotic DNA is packed around an octamer of 4 core histone proteins, two molecules each of $\mathrm{H} 4, \mathrm{H} 3, \mathrm{H} 2 \mathrm{~A}$ and $\mathrm{H} 2 \mathrm{~B}$. Chromatin lies at the crossroad of epigenetic reprogramming during early embryogenesis, and is subject to exquisite regulation through remodelling, covalent modifications of histones and replacement by histone variants (Morgan et al., 2005, Reik, 2007, TorresPadilla, 2008). Histones are essential targets for regulation of DNA-mediated processes including transcription, replication and DNA repair. Amongst the core histones, $\mathrm{H} 2 \mathrm{~A}$ has the highest number of variants, and some of them display specific functions in spermatogenesis and during preimplantation development (Faast et al., 2001, Govin et al., 2007). Loss of the H2A variant H2A.X in mice results in genome instability and male infertility (Celeste et al., 2002). Indeed, phosphorylation of the SQ motif on
H2A.X is necessary for efficient DSBs repair. Phosphorylation of H2A.X is focally enriched at DSBs sites upon DNA damage and is mediated by kinases of the PI3-K family including ataxia telangiectasia mutated (ATM), ATM and Rad-3 related (ATR) and the DNA-protein kinase (DNA-PK) in response to DNA damage (Stiff et al., 2004). Phosphorylation of H2A.X spreads along several megabases from the site of break and is believed to help to recruit, concentrate and retain the proteins that modify, remodell and repair DNA lesions. Thus, the phosphorylated form of H2A.X (referred to as $\gamma \mathrm{H} 2 \mathrm{~A}$.X) acts both as a DNA damage sensor as well as to amplify signals required to prevent cells with damaged DNA to enter into mitosis.

In human fibroblasts, $\mathrm{H} 2 \mathrm{~A}$.X represents $2-25 \%$ of the $\mathrm{H} 2 \mathrm{~A}$ pool (Rogakou et al., 1998). However, in Xenopus eggs, H2A.X is the
A
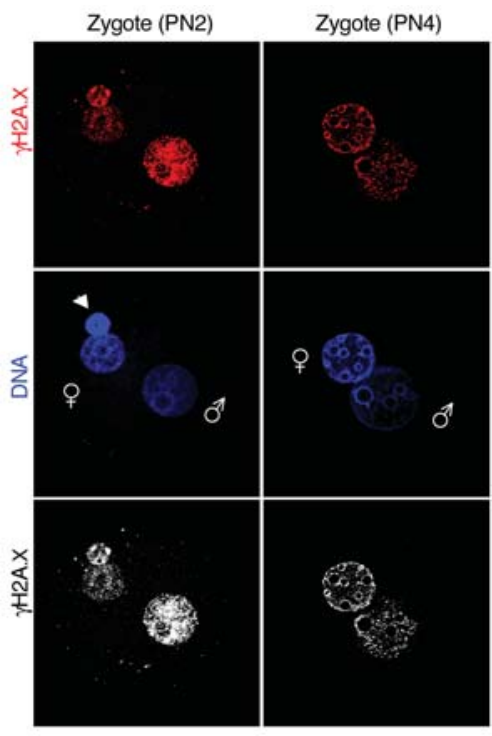

C

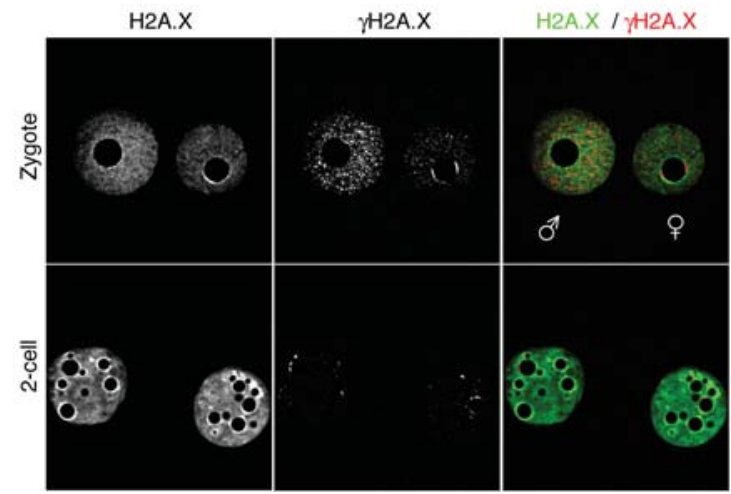

Zygote (PN4)
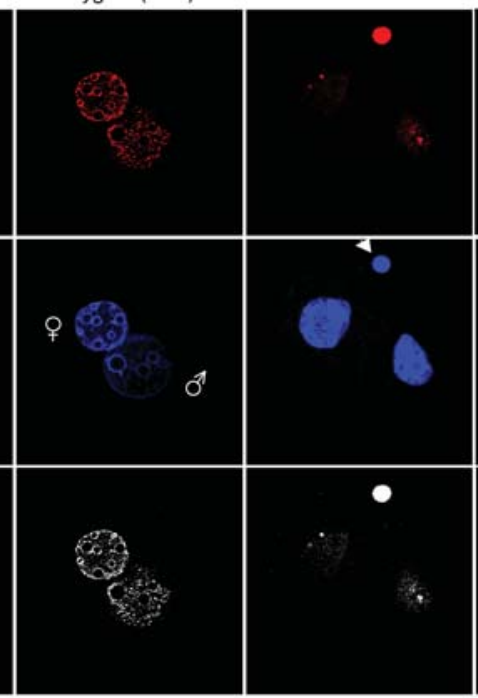

6.
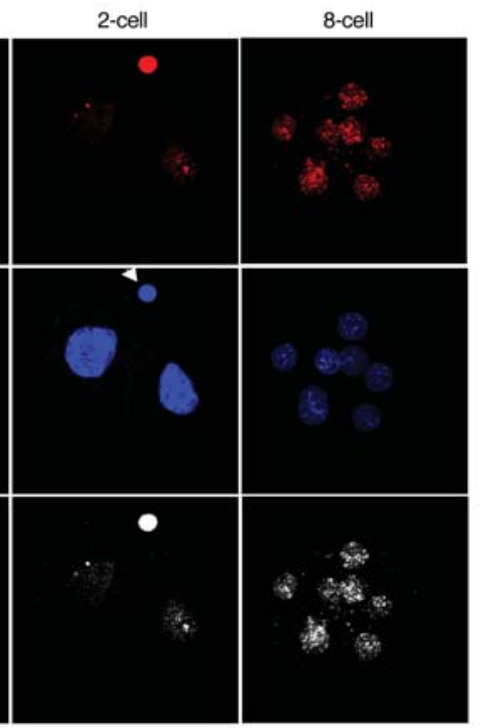

B

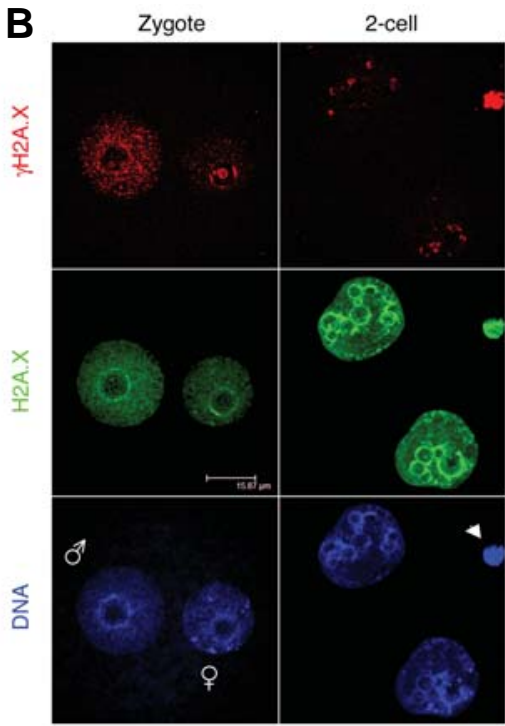

D
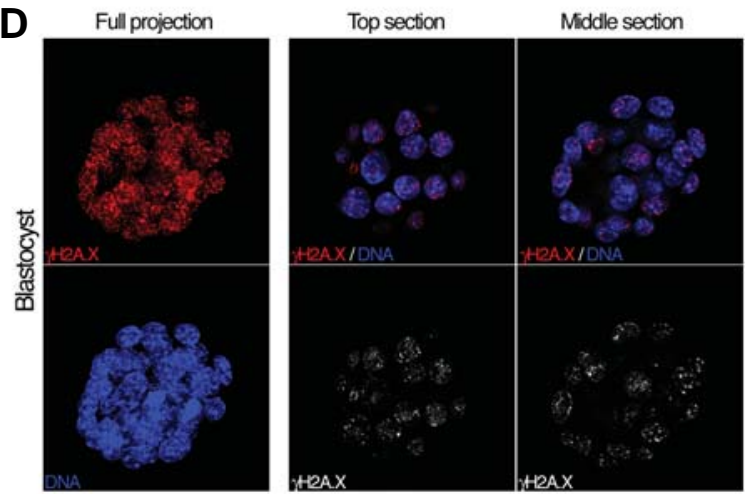

Fig. 1. Dynamics of phosphorylation of H2A.X during murine preimplantation development. (A) Embryos at the indicated stages were freshly collected, fixed, stained with a $\gamma H 2 A . X$ (red) antibody and analysed through confocal microscopy. DNA is shown in blue. Shown are full projections of Z-sections taken every $1 \mu \mathrm{m}$. All embryos are shown at the same magnification scale. The bottom panel is the same channel for $\gamma H 2 A$. $X$ shown at the top but in grayscale. When present, the polar body is indicated by an arrowhead. The male and female pronuclei are indicated. At least 10 embryos from independent experiments were analysed per stage. Embryos shown were imaged in parallel under identical conditions, thus fluorescence levels are directly comparable. (B,C) H2A.Xphosphorylation levels decrease between the zygote and the 2-cell stage. Zygotes and 2-cell stage embryos were fixed and processed for double immunostaining with $\gamma H 2 A . X$ and H2A.X antibodies. Embryos shown were processed in parallel under identical conditions. Note that H2A.X accumulation is sustained at the 2-cell stage. Shown are full projections (B) or middle sections (C) of Z-series taken every $1 \mu \mathrm{m}$. Male and female pronuclei are indicated. Where visible, the polar body is indicated by an arrowhead. (D) Blastocysts were fixed as in A and stained with the $\gamma H 2 A . X$ antibody. Shown is a full projection of stack series taken every $2 \mu \mathrm{m}$ for the $\gamma H 2 A$.X (red) and the DAPI (blue) channels. A merge and grayscale $(\gamma H 2 A . X)$ Top and Middle sections of the same blastocyst are shown in the middle and right panels. 
most abundant $\mathrm{H} 2 \mathrm{~A}$ variant, and the ability to remodel the sperm nucleus to form a paternal pronucleus after fertilisation is directly associated with phosphorylation of H2A.X (Dimitrov et al., 1994). This suggests that H2A.X might be involved in the series of steps required for chromatin assembly after fertilisation. Indeed, major changes of H2A.X phosphorylation occur concomitant with chromatin remodelling and over $50 \%$ of $\mathrm{H} 2 \mathrm{~A}$.X is stably phosphorylated in the decondensed sperm nucleus in Xenopus (Dimitrov et al., 1994). Although the changes in the phosphorylation state might not directly contribute to generating nucleosomes, stabilisation of phosphorylated state of H2A.X is involved in generating de novo nucleosomes with physiological spacing (Kleinschmidt and Steinbeisser, 1991). Thus, H2A.X has the potential of playing multiple roles during mouse embryogenesis.

53BP1 is an evolutionary conserved Tudor domain-containing protein that is also invoved in DNA damage-induced cell cycle arest (Wang et al., 2002). 53BP1 null mice are growth retarded and are prone to develop tumors (Ward et al., 2003). 53BP1 was originally identified as a p53 binding protein (Iwabuchi et al., 1994), it displays both, cytoplasmic as well as nuclear localisation and stimulates p53-mediated transcription (Iwabuchi etal., 1998). 53BP1 is also phosphorylated in an ATM-dependent manner and becomes gradually localised to DSBs (Anderson et al., 2001, Ward et al., 2006). Both, H2A.X-/- and 53BP1-/- cells display a G2/M arrest when DNA damage is unduced upon $\gamma$-irradiation (Fernandez-Capetillo et al., 2003a). Phosphorylated H2A.X is directly linked to the recruitment of 53BP1 into DSB foci, suggesting that they mediate DNA repair in similar pathways (FernandezCapetillo et al., 2003a). However, 53BP1 can participate in DNA repair independently of $\mathrm{H} 2 \mathrm{~A}$.X, most likely via its ability to interact with histone H4 (Botuyan et al., 2005, Sanders et al., 2004, Xie et al., 2007). Indeed, 53BP1 has been shown to bind to dimethylated lysine 20 of $\mathrm{H} 4$ (H4K20me2) and to a lesser extent, to H4K20me1 (Botuyan et al., 2005).

Whether these two proteins are present at early stages of development and how they are distributed in the blastomeres of the preimplantation embryo has not been addressed in full. Here we have examined the protein distribution of 53BP1 and $\gamma \mathrm{H} 2 \mathrm{~A}$.X. We found that phosphorylation of H2A.X persists throughout preimplantation development, with particularly high levels in the zygote right after fertilisation and after the 4-cell stage. We observed that phosphorylation of H2A.X increases during mitosis in the absence of induction of DNA damage. 53BP1 is detected on the embryonic chromatin only from the 2-cell stage onwards and is absent from mitotic chromosomes. We also found that 53BP1 and $\gamma \mathrm{H} 2 \mathrm{~A}$.X only rarely colocalise, suggesting that these high levels of phosphorylation of H2A.X are not directly linked to the DNA damage process in the early embryo. Our data suggest that phosphorylation of H2A.X is an important event in the embryo in the absence of any induced DNA damage and suggest that repair of DSB could be potentially activated in the early embryo.

\section{Results}

We first analysed the dynamics of phosphorylation of H2A.X during preimplantation development. We detected high levels of phosphorylated H2A.X in the zygote (Fig. 1A). At early stages of pronuclear development (PN2, (Adenot et al., 1997), the paternal pronucleus displayed higher levels of $\gamma \mathrm{H} 2 \mathrm{~A}$.X compared to the
A

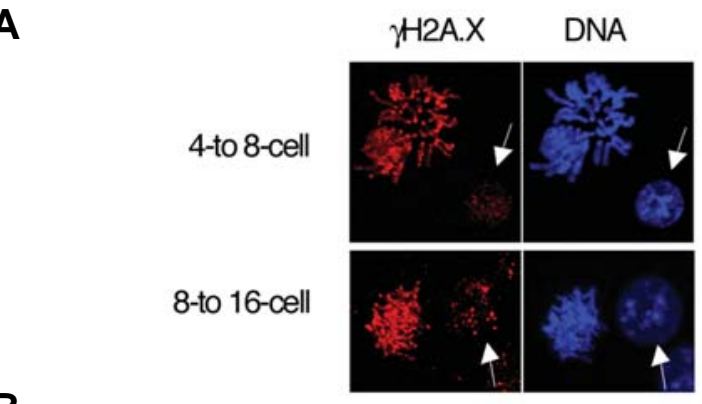

B

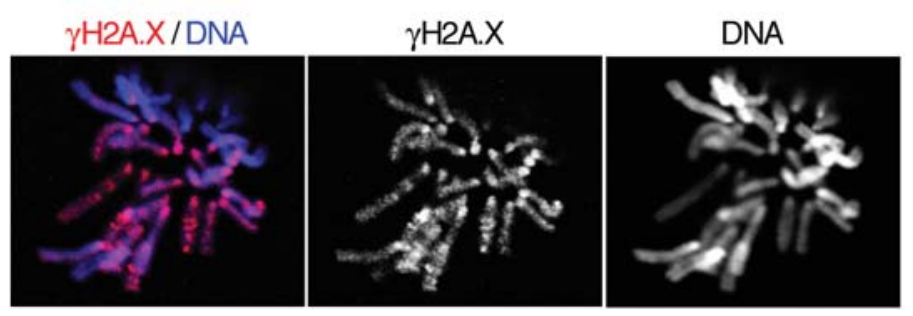

Fig. 2. Levels of $\boldsymbol{\gamma} \mathbf{H} \mathbf{2 A} . \mathbf{X}$ increase during mitosis. (A) Embryos were fixed and stained with the $\gamma H 2 A . X$ antibody (red). Shown are two cells from a 4- and an 8-cell stage embryo that are undergoing mitosis. The corresponding DNA labelling (blue) is shown at the right. Note the increased levels in the mitotic chromosomes compared to the interphasic cells (arrow) within the same embryo. These changes occur in the absence of any induced DNA damage. (B) Detail of mitotic chromosomes stained with $\gamma H 2 A . X$ (red) and DAPI (blue). Single confocal section of mitotic chromosomes of an 8-cell stage embryo. Merge (left) and grayscale (middle and right) images are shown.

maternal one ( $n=6$, Fig. 1A). At later stages of pronuclear development (PN4) $\gamma \mathrm{H} 2 \mathrm{~A}$.X levels were still readily detected in the two pronuclei. Higher levels of phosphorylation of H2A.X in the male pronucleus do not reflect a preferential incorporation of H2A.X in the paternal chromatin as both pronuclei were equally labelled with a H2A.X antibody (Fig. $1 \mathrm{~B}, \mathrm{C}$ ). At the 2-cell stage, phosphorylation of $\mathrm{H} 2 \mathrm{~A}$. $X$ decreased significantly compared to the zygote (Fig. 1A), and only 1 or 2 large foci per nucleus were detected. The polar body remained strongly stained by the $\gamma \mathrm{H} 2 \mathrm{~A}$.X antibody. Immunostaining of zygotes and 2-cell stage embryos with an $\mathrm{H} 2 \mathrm{~A}$.X antibody revealed strong and wide accumulation of $\mathrm{H} 2 \mathrm{~A}$.X in both pronuclei and in 2-cell stage embryos (Fig. $1 \mathrm{~B}, \mathrm{C}$ ). Thus, the decrease in $\gamma \mathrm{H} 2 \mathrm{~A}$.X levels at the 2-cell stage is not due to a reduction in the actual level of H2A.X. The levels of phosphorylated $\mathrm{H} 2 \mathrm{~A}$. $X$ were again high at the 8 -cell stage and remained so in the blastocyst (Fig. 1B). We did not detect any preferential distribution of $\gamma \mathrm{H} 2 \mathrm{~A}$.X between the inner cell mass or the trophectoderm in the blastocyst. Moreover, $\gamma \mathrm{H} 2 \mathrm{~A}$.X was not particularly associated with DAPI rich regions (Fig. 1B, merge images). Thus, $\mathrm{H} 2 \mathrm{~A} . \mathrm{X}$ is abundantly phosphorylated throughout preimplantation development and embryos seem to exhibit instrinsic high levels of $\gamma \mathrm{H} 2 \mathrm{~A} . \mathrm{X}$, even in the absence of DNA damage.

We next assessed whether levels of phosphorylated H2A.X vary during mitosis in the blastomeres of the early embryo. For this, we analysed the localisation of $\gamma \mathrm{H} 2 \mathrm{~A}$.X during the mitotic divisions of 4- and 8-cell stage embryos. Condensed mitotic chromosomes displayed even higher levels of $\gamma \mathrm{H} 2 \mathrm{~A} . \mathrm{X}$ compared to interphasic cells (Fig. 2A). $\gamma \mathrm{H} 2 \mathrm{~A} . \mathrm{X}$ described a band-like 
pattern on mitotic chromosomes, with a strong enrichment of $\gamma$ H2A.X in the telomeres (Fig. 2B). Thus, phosphorylation of H2A.X appears to be an active continous process during preimplantation development and levels of $\gamma \mathrm{H} 2 \mathrm{~A}$.X increase drastically during mitosis.

In somatic cells, the p53 binding protein 53BP1 has been shown to co-localise to chromatin in association to $\gamma \mathrm{H} 2 \mathrm{~A}$.X near double-strand breaks. However, 53BP1 and $\gamma \mathrm{H} 2 \mathrm{~A}$.X functions do not always depend on the same signals and have distinct roles in DSB repair (Celeste et al., 2003, Xiao et al., 2006). We thus investigated the expression and localisation of 53BP1 in preimplantation embryos. In contrast to $\gamma \mathrm{H} 2 \mathrm{~A}$.X, in zygotes right after fertilisation (PN0), 53BP1 was present only in the cytoplasm and was not associated to the anaphasic chromosomes on the female pronucleus or the forming male pronucleus, both containing condensed chromatin (Fig. 3A). At late pronuclear stages (PN4), 53BP1 exhibited predominantly cytoplasmic staining, but it was not excluded from the nucleus and some signal could be detected in the pronuclei (Fig. 3A). Within the pronuclei, we did not detect particular foci distribution or enrichment of 53BP1. At the 2-cell stage, 53BP1 still displayed some cytoplasmic staining, but the protein was clearly enriched in the nucleus. At this stage, a few large, intensely stained foci could be seen in some nuclei (usually 1 foci per nucleus, $n=8$ ) (Fig. 3A). At the 8-cell stage, nuclear

A
A Zygote (PNO)

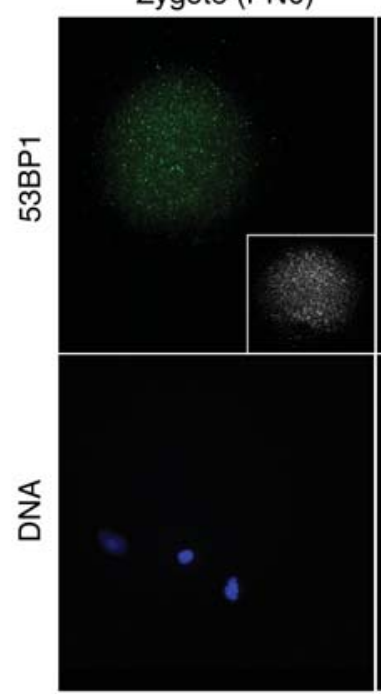

Zygote (PN4)

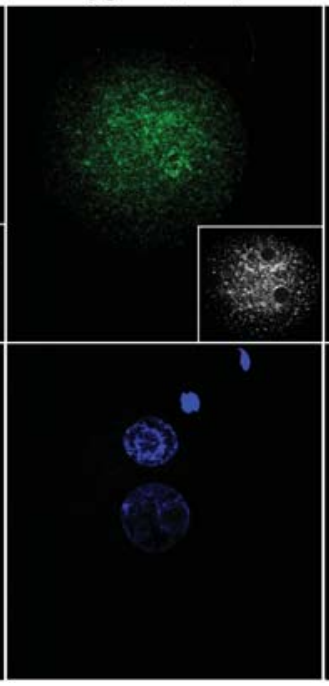

2-cell

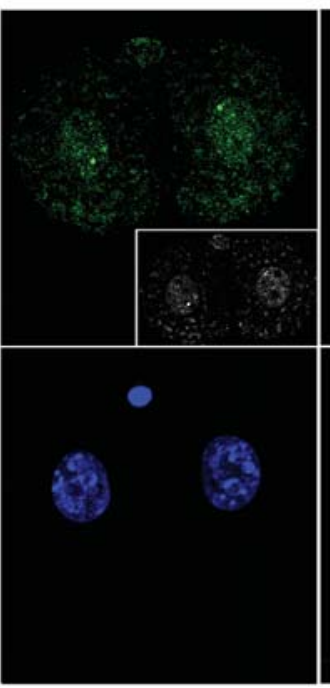

8-cell

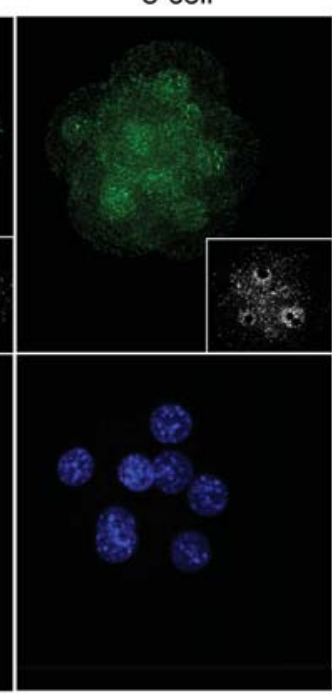

enrichment of 53BP1 was even more pronounced than in 2-cell stage embryos, but we could also detect 53BP1 staining in the cytoplasm. Between the 2- and the 8-cell stage, 53BP1 staining was punctate and excluded from the DAPI-rich heterochromatic regions. No particular association with any nuclear structure was detected (Fig. 3B).

At the morula stage, 53BP1 staining displayed a completely different pattern: the protein was mostly excluded from the nucleus and instead displayed a predominant cytoplasmic localisation. The observed cytoplasmic localisation was not an artifact of the antibody batch that we used, as culture cells stained with the same antibody showed a typical nuclear staining with some foci dispersed throughout the nucleus (Fig. 4E). While we detected 53BP1 in outer cells of the morula, inner cells displayed very low to undetectable levels of 53BP1 (Fig. 4A). A similar pattern of staining was observed at the blastocyst stage, where the inner cell mass cells appeared mostly devoided of 53BP1 and the trophectoderm cells were clearly enriched in 53BP1 (Fig. 4B). In these cells 53BP1 was again excluded from the nucleus (Fig. 4 B,C). However, in some embryos, we could detect $1-2$ cells next to the forming blastocoeilic cavity that displayed both cytoplasmic and nuclear localisation of 53BP1 (Fig. 4C, arrow). This suggests that the change of localisation of 53BP1 from the nucleus to the cytoplasm might be temporally regulated. The difference in 53BP1 staining in inner versus outer cells was not due to problems of antibody penetration as inner cells were labelled with a pan-acetyl $\mathrm{H} 4$ antibody (Fig. 4D). Further, in the blastocyst, Oct4 positive cells showed very low to undetectable levels of 53BP1 staining (Fig. 1F). Localisation of 53BP1 in trophectoderm cells was further confirmed by costaining with an antibody recognising $\mathrm{Cdx} 2$, which is specifically expressed in the trophectoderm (Strumpf et al., 2005)(Fig. $4 \mathrm{G})$. The predominant cytoplasmic localisation was not an artifact due to problems of antibody penetration into the nucleus, as the transcription factor $\mathrm{Cdx} 2$, showed a clear nuclear localisation. Thus, 53BP1 is expressed throughout

B

53BP1 / DNA

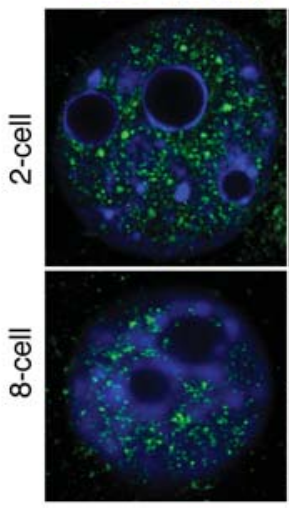

53BP1

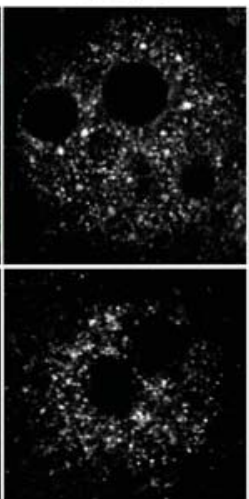

DNA

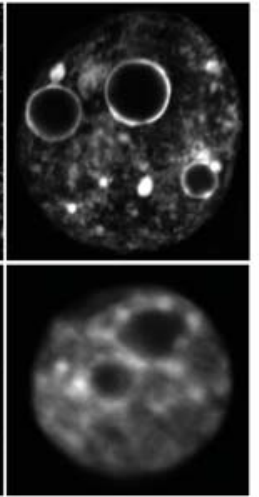

Fig. 3. Accumulation of 53BP1 during preimplantation development in the mouse. (A) Zygotes at pronuclear stages (PN) 0 and PN4, 2-cell stage and 8-cell stage embryos were fixed and processed for immunostaining with a 53BP1 antibody (green). DNA is shown in blue. Shown are full projections of Z-series taken every $1 \mu \mathrm{m}$ of representative embryos of at least 10 embryos analysed per stage. In the inset a representative single section of 53BP1 localisation in grayscale is shown. Note that nuclear enrichment of 53BP1 is only evident from the 2-cell stage onwards. Embryos were analysed in parallel and fluorescence levels are comparable between stages. (B) Nuclear accumulation of 53BP1 is punctated and in euchromatic regions. Single sections of nuclei of 2-and 8-cell stage embryos are shown. 53BP1 is distributed throughout the nucleoplasm and is mostly excluded from DAPI-rich regions. The round structures in 2-cell stage nuclei correspond to pericentric chromatin that surrounds the nucleolar-like bodies. This chromatin architecture is characteristic of the $1^{\text {st }}$ cleavage stages in the embryo. 
A
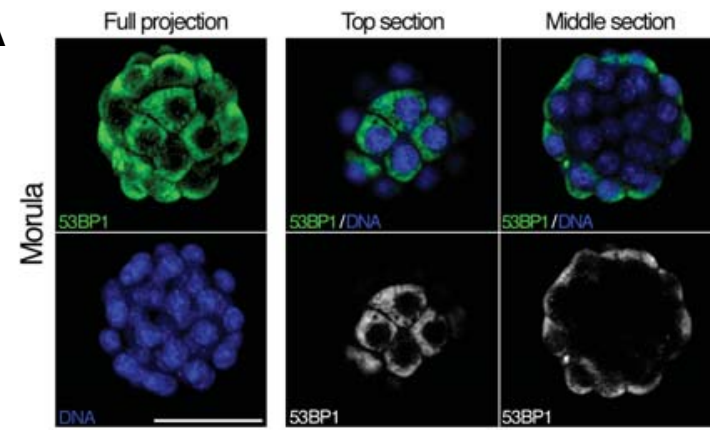

B
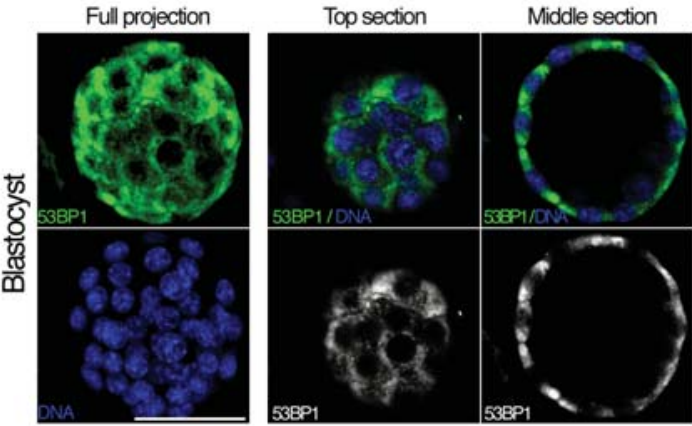

C

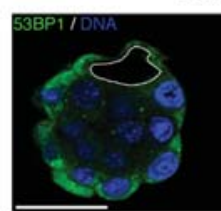

Early Blastocyst (single section)
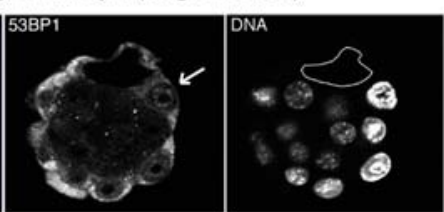

D
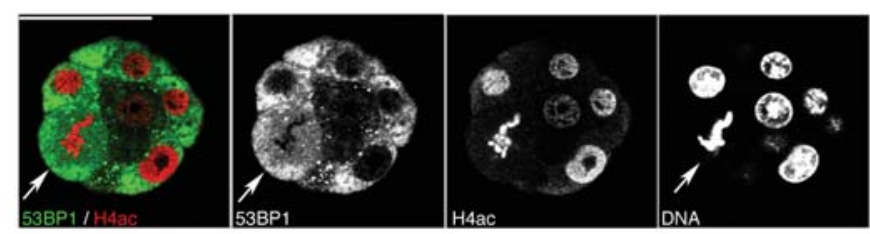

E
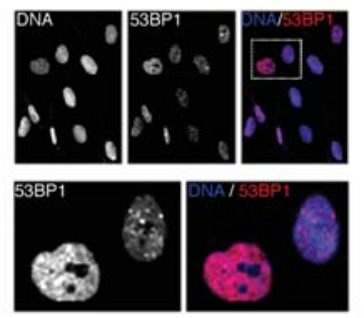

$\mathbf{F}$

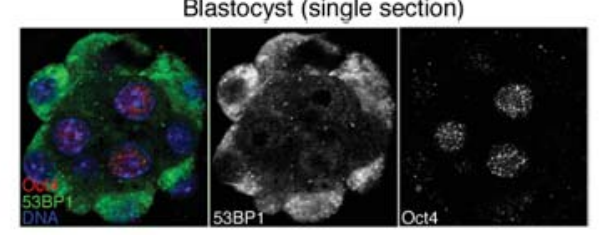

Blastocyst (single section)

G

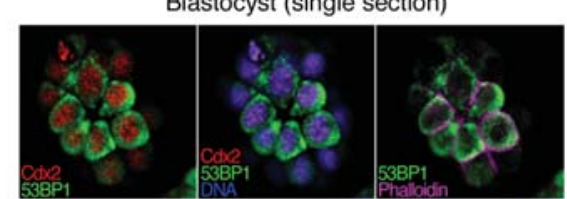

Fig. 4. Localisation of 53BP1 at the morula and blastocyst stage is predominantly cytoplasmic. (A) Morula stage embryos stained with the $53 B P 1$ antibody (green) and DAPI (blue). Embryos were fixed, processed for immunostaining and imaged under a confocal microscope. Shown are full projections of Z-sections taken every $2 \mu \mathrm{m}$ (left). Single top (middle panel) and middle sections (right) are displayed as merged or grayscale as indicated. 53BP1 is barely detectable in the inner cells of the embryo. Shown are representative embryos of 4 independent experiments and 41 embryos analysed per stage. Scale bar is $40 \mu \mathrm{m}$. (B) Pattern of 53BP1 localisation in the blastocyst. Embryos were analysed as in A. (C) Middle section of an early blastocyst stained with the 53BP1 antibody. Shown are the merge and grayscale images of green (53BP1) and blue (DAPI) channels. The arrow points to one cell in which some nuclear localisation of 53BP1 is still visible. Note that in all other outer cells 53BP1 localisation is mostly cytoplasmic. The white line in the merge and DNA panels delinates the forming blastocyst cavity. Scale bar is $40 \mu \mathrm{m}$. (D) Middle section of a morula stained with the 53BP1 and a pan-acetyl histone H4 antibody. Shown are the merge image of 53BP1 (green) and H4ac (red) and greyscale images of 53BP1, H4ac and DAPI channels as indicated. Scale bar is $40 \mu \mathrm{m}$. Embryo shown is representative of 8 embryos analysed. Note that $53 B P 1$ is not associated with mitotic chromatin (arrow). (E) Localisation of 53BP1 in culture cells is nuclear and displays a foci-like pattern. MHN cells were stained with the same 53BP1 antibody used for immunostaining of embryos. Shown are grayscale of the DAPI and red (53BP1) channels and a merge image. The inset in the merge panel is shown at a higher magnification (two bottom pannels). (F) Oct4-positive cells in the blastocyst are mostly devoided of 53BP1 staining. Shown are a middle section of merge (left) and grayscale images of 53BP1 and Oct4 staining. Shown are representative of 6 embryos analysed. (G) 53BP1 is enriched in the cytoplasm of trophectoderm cells in the blastocyst. Blastocysts were stained with the 53BP1 antibody and an antibody specific for $C d \times 2$, Phalloidin was used to reveal cell-cell boundaries. Shown is a detail of a blastocyst section containing trophectodermal cells as revealed by the presence of Cdx2 in the nucleus (red). DNA is shown in blue.

preimplantation development and its nuclear localisation is transitory, as the protein seems to be excluded from the nucleus just before implantation.

Because of the relationship between phosphorylation of H2A.X and subsequent recruitment of 53BP1, we further analysed whether $\gamma \mathrm{H} 2 \mathrm{~A} . \mathrm{X}$ and 53BP1 colocalise in the embryo. We performed double immunostaining with the 53BP1 and the $\gamma \mathrm{H} 2 \mathrm{~A}$.X antibodies. The punctate staining of 53BP1 that we described above did not colocalise with $\gamma \mathrm{H} 2 \mathrm{~A} . \mathrm{X}$ at any of the stages analysed (2-cell through blastocyst)(Fig. 5 and data not shown). Instead, only the large and densely stained 53BP1 foci at the 2-cell stage colocalised with $\gamma \mathrm{H} 2 \mathrm{~A}$.X (Fig. 5B), suggesting that these, but not the former, are likely to be sites of DNA damage.

\section{Discussion}

Expression at the mRNA level of some of the components of DNA repair cascades in the rat and human embryo has been 
A

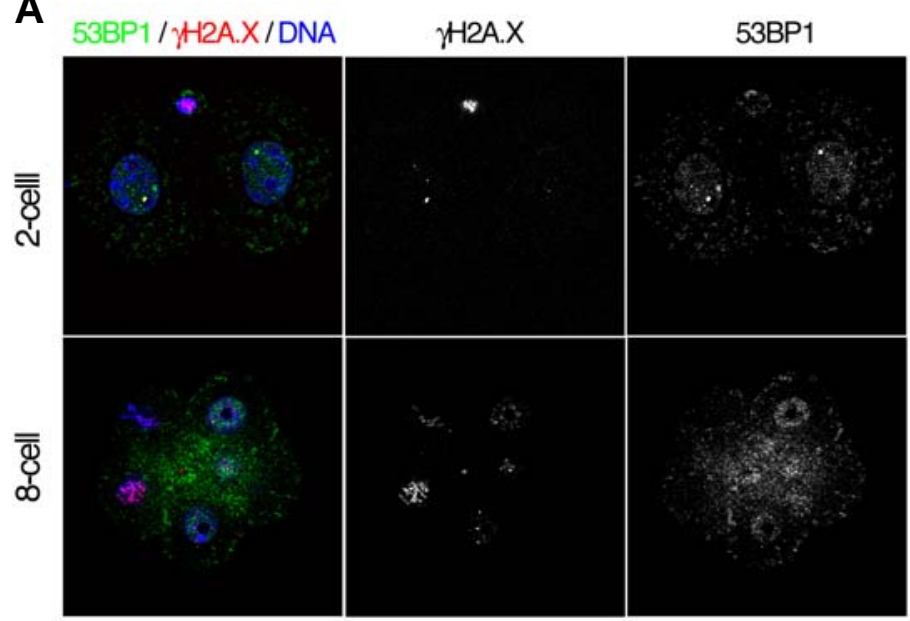

B

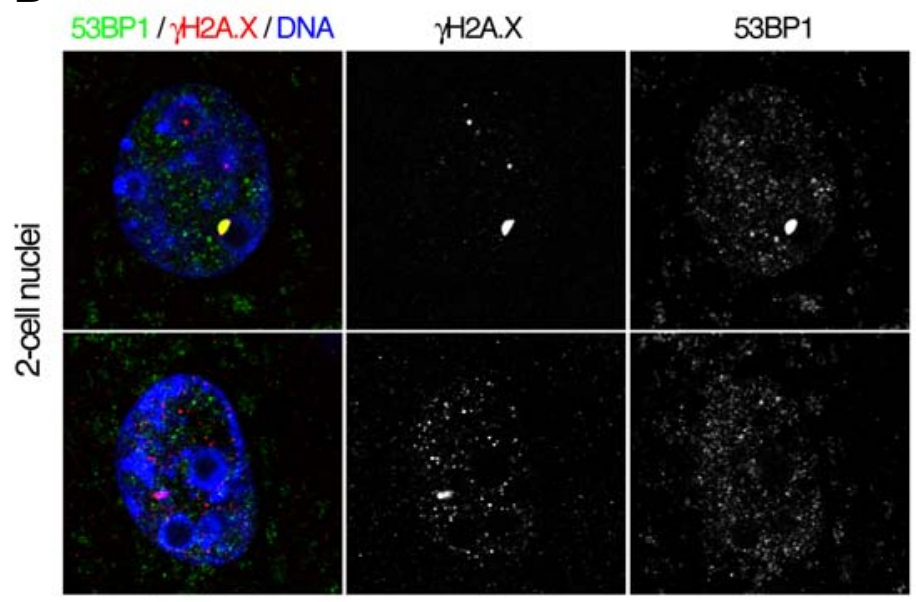

C

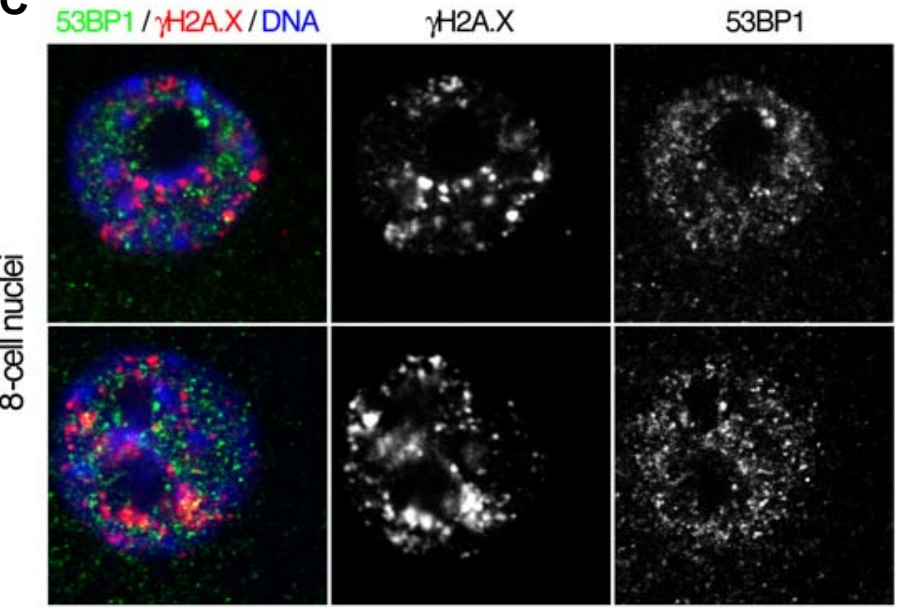

Fig. 5. Co-staining of 53BP1 and $\boldsymbol{\gamma} \mathrm{H} 2 \mathrm{~A} . \mathrm{X}$ shows rare colocalisation in the embryo. (A) Single confocal sections of 2- and 8-cell stage embryos stained with the 53BP1 (green) and $\gamma H 2 A . X$ (red) antibodies. DNA was stained with DAPI (blue). (B,C) Nuclei of embryos at the 2-cell (B) and 8cell (C) stage stained with the 53BP1 (green) and $\gamma H 2 A . X$ (red) antibodies. Shown are merge and grayscale images as indicated. Note that only large 53BP1 and $\gamma H 2 A . X$ foci colocalise and overall, the punctate stainings of both proteins do not colocalise. recently collected from the literature and put together in a review (Jaroudi and SenGupta, 2007). This analysis suggests that a variety of DNA repair pathways can be potentially triggered during embryonic development as most components were found to be expressed in the human and rat embryo. However, no systematic analysis of protein localisation and expression in the early mouse embryo has been performed. Such analyses are especially important because transcription and translation are often uncoupled in the embryo (Schultz, 2002).

Because of the crucial role of $\gamma \mathrm{H} 2 \mathrm{~A} . \mathrm{X}$ in the DNA damage response as well as its putative role in assembly of embryonic chromatin, we started by analysing its distribution in the preimplantation mouse embryo. Most importantly, our work documents for the first time the patterns of $\gamma \mathrm{H} 2 \mathrm{~A}$.X and 53BP1 localisation in freshly collected embryos. Patterns of $\gamma \mathrm{H} 2 \mathrm{~A}$.X in the embryo have been previously analysed in response to DSBs caused by $\gamma$ irradiation in in vitro fertilised embryos (Derijck et al., 2006, Yukawa et al., 2007), but not under normal conditions in the absence of DNA damage in freshly collected embryos. This is particularly relevant as in vitro fertilisation procedures and/or culture environment could have important effects in the abundance of histone modifications or DNA methylation patterns (Li et al., 2005, van der Heijden et al., 2009). Derijck et al., (Derijck et al., 2006) have followed $\gamma \mathrm{H} 2 \mathrm{~A}$.X levels in zygotes fertilised in vitro with $\gamma$-irradiated sperm and exposed to the DNA-damaging agent etoposide. Interestingly, they document a different degree of H2A.X phosphorylation responsiveness to DNA damage between male and female chromatin, in line with our observations. Our work contrasts to a report published earlier by Adiga et al., where basal levels of $\gamma \mathrm{H} 2 \mathrm{~A}$.X are undetectable in normal embryos (Adiga et al., 2007). This is very likely due to different immunostaining protocols and techniques (e.g. non complete permeabilisation and specially, the use of normal epifluorescence microscope as opposed to the use of confocal acquisition). The protocol that we used here has been optimised for preserving cellular structures and achieving an efficient permeabilisation to the nucleus without damaging its structure (for example fixation is performed at $37^{\circ}$ ) (Torres-Padilla and Zernicka-Goetz, 2006, Torres-Padilla et al., 2006, Torres-Padilla et al., 2007).

We have found that levels of $\gamma \mathrm{H} 2 \mathrm{~A} . \mathrm{X}$ are sustained in the embryo in the absence of induced DNA damage. This is in line with previous reports documenting phosphorylation of H2A.X independent of DNA damage (McManus and Hendzel, 2005). In particular, we observed very high levels of phosphorylated H2A.X in the zygote right after fertilisation, with a small, but clear asymmetry between the male and the female pronucleus. Because phosphorylated H2A.X plays an important role in the generation of nucleosome arrays with physiological spacing properties (Kleinschmidt and Steinbeisser, 1991) we suggest that the high levels of $\gamma \mathrm{H} 2 \mathrm{~A}$.X in the male pronucleus might reflect the fact that this constitutes newly assembled chromatin that needs to achieve a proper nucleosomal configuration. Additionally, high levels of $\gamma \mathrm{H} 2 \mathrm{~A}$.X could reflect an intense repair process in the male pronucleus compared to the female one. After fertilisation, both the maternal and the paternal chromatin undergo epigenetic reprogramming, which includes a decrease in global levels of DNA methylation (Li, 2002, Morgan et al., 2005, Santos et al., 2002). While female chromatin is passively demethylated (e.g. through replication), the paternal chromatin is believed to un- 
dergo an active DNA demethylation process before replication (Mayer et al., 2000). DNA demethylation occuring in the male pronucleus has been suggested to be mediated via the repair pathway (Branco et al., 2008, Reik, 2007), high levels of $\gamma \mathrm{H} 2 \mathrm{~A} . \mathrm{X}$ might provide support for this hypothesis. Thus, the high levels of H2A.X phosphorylation that we observed might be related to reprogramming in the embryo. Indeed, H2A.X plays an important role in chromatin remodelling in male meiosis (Fernandez-Capetillo et al., 2003b). However, whether there is a direct relationship between phosphorylation of H2A.X and DNA demethylation remains to be determined.

We found that phosphorylation of H2A.X varies along the cell cycle in the embryo, with highest levels displayed during mitosis. Changes in the levels of phosphorylation of $\mathrm{H} 2 \mathrm{~A}$.X have also been observed in normally growing and non-radiated mammalian cells in culture and primary cells. These changes in the phosphorylation levels of H2A.X were suggested to be cell cycle regulated, as ATM-dependent phosphorylation of H2A.X is maximal at mitosis (Ichijima et al., 2005, McManus and Hendzel, 2005). Phosphorylation of H2A.X may thus contribute to the proper course of mitosis. In support, a non-phosphorylatable S134A mutation of H2A.X in Tetrahymenaresults in impaired cell division (Xiaoyuan et al., 2007). High levels of H2A.X phosphorylation could also be related to the replicative stress in fast dividing cells. Thus, high levels of $\gamma \mathrm{H} 2 \mathrm{~A}$.X during mitosis in embryonic cells could be relevant for mitotic progression during the intense phase of cell division that the embryo undergoes before implantation.

We found that phosphorylated H2A.X is focally enriched in mitotic telomeres from the 4-cell stage. In senescence cells, where telomerase activity decreases, telomeres accumulate $\gamma \mathrm{H} 2 \mathrm{~A} . \mathrm{X}$ foci (Meier et al., 2007). Because telomerase activity is high in germ cells, but lower in cleavage stage embryos, telomeres lengthen drastically during preimplantation development (Liu et al., 2007). Sister-chromatid exchange at the telomeres and colocalisation of the DNA recombination proteins Rad50 and TRF1 have been documented during these stages of development (Liu et al., 2007). Indeed, high levels of $\gamma \mathrm{H} 2 \mathrm{~A}$.X at telomeres may result from telomere lengthening, which has been suggested to occur through a recombination-based mechanims in cleavage stage embryos (Liu et al., 2007).

Outside of mitosis, two types of $\gamma \mathrm{H} 2 \mathrm{~A}$.X foci have been described in interphasic nuclei of non-irradiated cultured cells: large foci, which colocalise with a number of DSB repair proteins, and much smaller foci (McManus and Hendzel, 2005). The latter foci look similar in appearance to the punctate pattern that we describe in the interphasic blastomeres in the embryo in this work and are therefore likely to reflect other functions of $\gamma \mathrm{H} 2 \mathrm{~A} . \mathrm{X}$ than repair. Indeed, we found that the small punctate foci only rarely colocalise with 53BP1. This suggests that the foci where the two proteins colocalise are perhaps indicative of DNA repair, while the remaining foci, which are smaller and more broadly distributed through the nucleoplasm could correspond to sites where phosphorylation of H2A.X could be important for chromatin structure. Of note, these small $\gamma \mathrm{H} 2 \mathrm{~A} . \mathrm{X}$ foci are present both in euchromatin as well as in heterochromatin.

Lastly, 53BP1 was present throughout preimplantation development from the 2-cell stage onwards and its cellular localisation changed drastically upon blastocyst formation, with a marked cytoplasmic accumulation in trophectoderm cells. In order to sustain implantation of the embryo, trophoblast cells differentiate into giant cells. This involves a switch from a proliferative cell cycle to an endocycle in which DNA undergoes many rounds of replication without cell division. Downregulation of p53 activity in trophoblast cells -mediated at least partially through cytoplasmic retention- participates in this transition by allowing the cell to overcome cell cycle checkpoints (Cohen et al., 2007, Soloveva and Linzer, 2004). Although we cannot exclude the possibility of 53BP1 being subject to a post-translational modification resulting in epitope exclusion in the nucleus, the gradual cytoplasmic retention of 53BP1 in the trophectoderm that we report here is in agreement with findings in human trophoblast, where p53 is also retained in the cytoplasm (Cohen et al., 2007, Soloveva and Linzer, 2004). Our findings suggest that this temporally regulated change in 53BP1 localisation contributes to reducing p53 function in trophoblast cells thereby allowing further differentiation for successfull implantation. In the future, it will be interesting to assess whether cytoplasmic 53BP1 locailsation becomes nuclear after DNA damage is induced.

In summary, we have shown that phosphorylation of H2A.X occurs in the mouse embryo as early as the zygote stage immediately after fertilisation, opening the possibility for a role in chromatin assembly and remodelling during these stages. Levels of $\gamma \mathrm{H} 2 \mathrm{~A}$.X occur in the absence of induced DNA damage and vary throughout the cell cycle, suggesting a role in mitosis during periods of fast division. Moreover, subcellular localisation of 53BP1 appears to be regulated in a temporal fashion during development. Our data contributes to the analysis of chromatinassociated proteins present throughout preimplantation development that could be potentially involved in epigenetic reprogramming.

\section{Materials \& Methods}

\section{Embryo collection and culture}

Mice were bred in a $12 \mathrm{~h}$ light cycle. Embryos were collected as described (Hogan et al., 1994) from CD1 6 weeks-old females that were crossed with CD1 males upon natural matings. Briefly, zygotes and cleavage stage embryos were collected at the indicated developmental stages upon puncturing of the ampulla swollen and the oviduct, respectively. Blastocysts were obtained by flushing the uterus with M2 medium (Sigma) as described (Hogan et al., 1994). Experiments with animals were carried out according to valid legislation in France. Pronuclear stages (PN) were classified according to Adenot et al. (1997).

\section{Immunostaining}

Embryos were fixed immediately after collection. After removal of the zona pellucida with acid Tyrode's solution (Sigma), embryos were washed three times in PBS and fixed as described (Torres-Padilla et al., 2006). Fixation was performed at $37^{\circ}$ to ensure preservation of nuclear architecture. After permeabilisation with $0.5 \%$ Triton, embryos were washed three times in PBS-T $(0.1 \%$ Tween in PBS), blocked and incubated with the primary antibodies in 3\% BSA $0.1 \%$ Tween in PBS for $\sim 12 \mathrm{~h}$ at $4{ }^{\circ} \mathrm{C}$. Antibodies used were: anti-phosho H2A.X antibody, Upstate 05-636, 1:500 dilution; anti 53BP1 antibody, Novus Biologicals, 1:100 dilution; anti-Cdx2 antibody, BioGenex CDX2-88, 1:75 dilution; anti-Oct4 antibody, BD 611202 1:100 dilution; anti H2A.X antibody, Abcam ab11175, 1:250 dilution; anti pan-acetylated H4, IGBMC, 1:150 dilution. 53BP1 and $\gamma \mathrm{H} 2 \mathrm{~A}$.X antibodies used in this work have been widely used in previous reports (see for example (Difilippantonio et al., 2005, Toledo et al., 2008). Embryos were then washed twice in PBS-T, blocked for 30 minutes and 
incubated for $2 \mathrm{~h}$ at $25^{\circ} \mathrm{C}$ with the corresponding secondary antibodies in $3 \%$ BSA in PBS-T. Secondary antibodies used were: A488-conjugated goat anti rabbit IgG, Molecular probes or Cy3-conjugated goat anti mouse, Jackson ImmunoResearch. After washing, DNA was stained with 4'-6-Diamidino-2-phenylindole (DAPI) and embryos were mounted in Vectashield (Vector Laboratories). For visualizing cell-cell boundaries, blastocysts were stained with Alexa Fluor 635 phalloidin (Molecular Probes). MHN (human normal myoblasts) were grown on a glass slide in MEM supplemented with $20 \%$ FCS, fixed with $4 \%$ paraformaldehyde, permeabilised with $0.5 \%$ Triton X-100 in PBS and blocked in $1 \%$ BSA prior to addition of the 53BP1 antibody.

\section{Confocal analysis}

Confocal microscopy was performed using a $63 x$ oil objective in a Leica SP2 UV inverted microscope (zygotes and cleavage stages). Sections were taken every 0.5 or $1 \mu \mathrm{m}$ as indicated in the figure legends. For imaging of blastocysts a 40x oil objective in a Leica SP2 AOBS MP confocal was used and sections were taken every $2 \mu \mathrm{m}$. All the stainings were repeated independently at least two times with at least 10 embryos analysed per stage.

\section{Acknowledgements \\ M.E.T.-P. acknowledges funding from the PNRRE and Avenir pro- grams from the Inserm.}

\section{References}

ADENOT, P.G., MERCIER, Y., RENARD, J.P. and THOMPSON, E.M. (1997). Differential h4 acetylation of paternal and maternal chromatin precedes DNA replication and differential transcriptional activity in pronuclei of 1-cell mouse embryos. Development 124: 4615-4625.

ADIGA, S.K., TOYOSHIMA, M., SHIMURA, T., TAKEDA, J., UEMATSU, N. and NIWA, O. (2007). Delayed and stage specific phosphorylation of h2ax during preimplantation development of gamma-irradiated mouse embryos. Reproduction 133: 415-422.

ANDERSON, L., HENDERSON, C. and ADACHI, Y. (2001). Phosphorylation and rapid relocalization of 53bp1 to nuclear foci upon DNA damage. Mo/ Cel/ Bio/21: 1719-1729.

BOTUYAN, M.V., LEE, J., WARD, I.M., KIM, J.E., THOMPSON, J.R., CHEN, J. and MER, G. (2005). Structural basis for the methylation state-specific recognition of histone h4-k20 by 53bp1 and crb2 in DNA repair. Cel/127: 1361-1373.

BRANCO, M.R., ODA, M. and REIK, W. (2008). Safeguarding parental identity: Dnmt1 maintains imprints during epigenetic reprogramming in early embryogenesis. Genes Dev22: 1567-1571.

CELESTE, A., FERNANDEZ-CAPETILLO, O., KRUHLAK, M.J., PILCH, D.R., STAUDT, D.W., LEE, A., BONNER, R.F., BONNER, W.M. and NUSSENZWEIG, A. (2003). Histone h2ax phosphorylation is dispensable for the initial recognition of DNA breaks. Nat Cel/ Bio/5: 675-679.

CELESTE, A., PETERSEN, S., ROMANIENKO, P.J., FERNANDEZ-CAPETILLO, O., CHEN, H.T., SEDELNIKOVA, O.A., REINA-SAN-MARTIN, B., COPPOLA, V., MEFFRE, E., DIFILIPPANTONIO, M.J. et al. (2002). Genomic instability in mice lacking histone h2ax. Science 296: 922-927.

COHEN, M., MEISSER, A., HAENGGELI, L., IRMINGER-FINGER, I. and BISCHOF, P. (2007). Status of p53 in first-trimester cytotrophoblastic cells. Mol Hum Reprod 13: 111-116.

DERIJCK, A.A., VAN DER HEIJDEN, G.W., GIELE, M., PHILIPPENS, M.E., VAN BAVEL, C.C.A.W. and DE BOER, P. (2006). Gammah2ax signalling during sperm chromatin remodelling in the mouse zygote. DNA Repair 5: 959-971.

DIFILIPPANTONIO, M.J., CELESTE, A., FERNANDEZ-CAPETILLO, O., CHEN, H.T., REINA-SAN-MARTIN, B., VAN LAETHEM, F., YANG, Y.P., PETUKHOVA, G.V., ECKHAUS, M., FEIGENBAUM, L. et al. (2005). Role of nbs1 in the activation of the atm kinase revealed in humanized mouse models. Nat Cel/ Biol 7: 675-685.

DIMITROV, S., DASSO, M.C. and WOLFFE, A.P. (1994). Remodeling sperm chromatin in Xenopus laevis egg extracts: The role of core histone phosphory- lation and linker histone b4 in chromatin assembly. J Cel/ Bio/126: 591-601.

FAAST, R., THONGLAIROAM, V., SCHULZ, T.C., BEALL, J., WELLS, J.R., TAYLOR, H., MATTHAEI, K., RATHJEN, P.D., TREMETHICK, D.J. and LYONS, I. (2001). Histone variant $h 2 a . Z$ is required for early mammalian development. Curr Bio/11: 1183-1187.

FERNANDEZ-CAPETILLO, O., CHEN, H.T., CELESTE, A., WARD, I., ROMANIENKO, P.J., MORALES, J.C., NAKA, K., XIA, Z., CAMERINI-OTERO, R.D., MOTOYAMA, N. et al. (2003a). DNA damage-induced g2-m checkpoint activation by histone h2ax and 53bp1. Nat Ce/l Bio/4: 993-997.

FERNANDEZ-CAPETILLO, O., MAHADEVAIAH, S.K., CELESTE, A., ROMANIENKO, P.J., CAMERINI-OTERO, R.D., BONNER, R.F., MANOVA, K., BURGOYNE, P. and NUSSENZWEIG, A. (2003b). H2ax is required for chromatin remodelling and inactivation of sex chromosomes in male mouse meiosis. Dev Cel/4: 497-508.

GOVIN, J., ESCOFFIER, E., ROUSSEAUX, S., KUHN, L., FERRO, M., THEVENON, J., CATENA, R., DAVIDSON, I., GARIN, J., KHOCHBIN, S. et al. (2007). Pericentric heterochromatin reprogramming by new histone variants during mouse spermiogenesis. J Cel/ Bio/176: 283-294.

HOGAN, B.L., BEDDINGTON, R., COSTANTINI, F. and LACY, E. (1994). Manipulating the mouse embryo. Cold Spring Harbor Laboratory Press.

ICHIJIMA, Y., SAKASAI, R., OKITA, N., ASAHINA, K., MIZUTANI, S. and TERAOKA, H. (2005). Phosphorylation of histone h2ax at $m$ phase in human cells without DNA damage response. Biochem Biophys Res Commun 336: 807-812.

ISMAIL, H.I. and HENDZEL, M.J. (2008). The g-h2a.X: Is it just a surrogate marker of double-strand breaks or much more? Environmental and Molecular Mutagenesis 49: 73-82.

IWABUCHI, K., BARTEL, P.L., LI, B., MARRACCINO, R. and FIELDS, S. (1994). Two cellular proteins that bind to wild-type but not mutant p53. Proc Nat/ Acad Sci U S A America 91: 6098-6102.

IWABUCHI, K., LI, B., MASSA, H.F., TRASK, B.J., DATE, T. and FIELDS, S. (1998) Stimulation of p53-mediated transcriptional activation by the p53-binding proteins, 53bp1 and 53bp2. J Biol Chem 273: 26061-26068.

JAROUDI, S. and SENGUPTA, S. (2007). DNA repair in mammalian embryos. Mutat Res 635: 53-77.

KLEINSCHMIDT, J.A. and STEINBEISSER, H. (1991). DNA-dependent phosphorylation of histone h2a.X during nucleosome assembly in Xenopus laevis oocytes: Involvement of protein phosphorylation in nucleosome spacing. Embo J10: 3043-3050.

$\mathrm{LI}, \mathrm{E}$. (2002). Chromatin modification and epigenetic reprogramming in mammalian development. Nat Rev Genet 3: 662-673.

LI, T., VU, T.H., ULANER, G.A., LITTMAN, E., LING, J.Q., CHEN, H.L., HU, J.F., BEHR, B., GIUDICE, L. and HOFMANN, A.R. (2005). Ivf results in de novo DNA methylation and histone methylation at an igf2-h19 imprinting epigenetic switch. Mol Hum Reprod 11: 631-640.

LIU, L., BAILEY, S.M., OKUKA, M., MUNOZ, P., LI, C., ZHOU, L., WU, C., CZERWIEC, E., SANDLER, L., SEYFANG, A. et al. (2007). Telomere lengthening early in development. Nat Cel/ Bio/9: 1436-1441.

MAYER, W., NIVELEAU, A., WALTER, J., FUNDELE, R. and HAAF, T. (2000). Demethylation of the zygotic paternal genome. Nature 403: 501-502.

MCMANUS, K.J. and HENDZEL, M.J. (2005). Atm-dependent DNA damageindependent mitotic phosphorylation of h2ax in normally growing mammalian cells. Mol Biol Cell 16: 5013-5025.

MEIER, A., FIEGLER, H., MUNOZ, P., ELLIS, P., RIGLER, D., LANGFORD, C. BLASCO, M.A., CARTER, N. and JACKSON, S.P. (2007). Spreading of mammalian DNA-damage response factors studied by chip-chip at damaged telomeres. Embo J26: 2707-18.

MORGAN, H.D., SANTOS, F., GREEN, K., DEAN, W. and REIK, W. (2005). Epigenetic reprogramming in mammals. Hum Mol Genet 14: R47-R58.

REIK, W. (2007). Stability and flexibility of epigenetic gene regulation in mammalian development. Nature 447: 425-432.

ROGAKOU, E.P., PILCH, D.R., ORR, A.H., IVANOVA, V.S. and BONNER, W.M (1998). DNA double-stranded breaks induce histone h2ax phosphorylation on serine 139. J Biol Chem 273: 5858-5868.

SANDERS, S.L., PORTOSO, M., MATA, J., BAHLER, J., ALLSHIRE, R.C. and KOUZARIDES, T. (2004). Methylation of histone h4 lysine 20 controls recruitment of crb2 to sites of DNA damage. Cel/119: 603-614. 
SANTOS, F., HENDRICH, B., REIK, W. and DEAN, W. (2002). Dynamic reprogramming of DNA methylation in the early mouse embryo. Dev Bio/241: 172-182.

SCHULTZ, R.M. (2002). The molecular foundations of the maternal to zygotic transition in the preimplantation embryo. Hum Reprod Update 8: 323-331.

SOLOVEVA, V. and LINZER, D.I. (2004). Differentiation of placental trophoblast giant cells requires downregulation of p53 and rb. Placenta 25: 29-36.

STIFF, T., O'DRISCOLL, M., RIEF, N., IWABUCHI, K., LOBRICH, M. and JEGGO, P.A. (2004). Atm and DNA-pk function redundantly to phosphorylate h2ax after exposure to ionizing radiation. Cancer Res 64: 2390-2396.

STRUMPF, D., MAO, C.A., YAMANAKA, Y., RALSTON, A., CHAWENGSAKSOPHAK, K., BECK, F. and ROSSANT, J. (2005). Cdx2 is required for correct cell fate specification and differentiation of trophectoderm in the mouse blastocyst. Development 132: 2093-2102.

TOlEDO, L.I., MURGA, M., GUTIERREZ-MARTINEZ, P., SORIA, R. and FERNANDEZ-CAPETILLO, O. (2008). Atr signaling can drive cells into senescence in the absence of DNA breaks. Genes Dev 22: 297-302.

TORRES-PADILLA, M. and ZERNICKA-GOETZ, M. (2006). Role of tif1 $\alpha$ as a modulator of embryonic transcription in the mouse zygote. Journal of Cell Biology 174: 329-338.

TORRES-PADILLA, M.E. (2008). Cell identity in the preimplantation mammalian embryo: An epigenetic perspective from the mouse. Hum Reprod. 23: 12461252.

TORRES-PADILLA, M.E., BANNISTER, A.J., HURD, P.J., KOUZARIDES, T. and ZERNICKA-GOETZ, M. (2006). Dynamic distribution of the replacement histone variant h3.3 in the mouse oocyte and preimplantation embryos. Int J Dev Bio/50: 455-461

TORRES-PADILLA, M.E., PARFITT, D.E., KOUZARIDES, T. and ZERNICKAGOETZ, M. (2007). Histone arginine methylation regulates pluripotency in the early mouse embryo. Nature 445: 214-218.

VAN DER HEIJDEN, G.W., VAN DER BERG, I.M., BAART, E.B., DERIJCK, A.A. MARTINI, E. and DE BOER, P. (2009). Parental origin of chromatin in human monopronuclear zygotes revealed by asymmetric histone methylation patterns, differs between ivf and icsi. Mol Reprod Dev 76: 101-108.

WANG, B., MATSUOKA, S., CARPENTER, P.B. and ELLEDGE, S.J. (2002). 53bp1, a mediator of the DNA damage checkpoint. Science 298: 1435-1438.

WARD, I., KIM, J.E., MINN, K., CHINI, C.C., MER, G. and CHEN, J. (2006). The tandem brct domain of 53bp1 is not required for its repair function. $J$ Biol Chem 281: 38472-38477.

WARD, I.M., MINN, K., VAN DEURSEN, J. and CHEN, J. (2003). P53 binding protein 53bp1 is required for DNA damage responses and tumor suppression in mice. Mol Cell Bio/23: 2556-2563.

XIAO, L., KIM, M. and DEJONG, J. (2006). Developmental and cell type-specific regulation of core promoter transcription factors in germ cells of frogs and mice. Gene Expr Patterns 6: 409-419.

XIAOYUAN, S., GJONESKA, E., REN, Q., TAVERNA, S.D., ALLIS, C.D. and GOROVSKY, M.A. (2007). Phosphorylation of the sq h2a.X motif is required for proper meiosis and mitosis in tetrahymena thermophila. Mo/ Cel/ Bio/27: 26482660.

XIE, A., haRTlerode, A., StUCKI, M., ODATE, S., PUGET, N., KWOK, A., NAGARAJU, G., YAN, C., ALT, F.W., CHEN, J. et al. (2007). Distinct roles of chromatin-associated proteins mdc1 and 53bp1 in mammalian double-strand break repair. Mol Cel/28: 1045-1057.

YUKAWA, M., ODA, S., MITANI, H., NAGATA, M. and AOKI, F. (2007). Deficiency in the response to DNA double-strand breaks in mouse early preimplantation embryos. Biochem Biophys Res Commun 358: 578-584.

\section{Further Related Reading, published previously in the Int. J. Dev. Biol.}

See our recent Special Issue Fertilization, in honor of David L. Garbers and edited by Paul M. Wassarman and Victor D. Vacquier at: http://www.ijdb.ehu.es/web/contents. php?vol=52\&issue=5-6

Dynamic distribution of the replacement histone variant $\mathrm{H} 3.3$ in the mouse oocyte and preimplantation embryos

Maria-Elena Torres-Padilla, Andrew J. Bannister, Paul J. Hurd, Tony Kouzarides and

Magdalena Zernicka-Goetz

Int. J. Dev. Biol. (2006) 50: 455-461

Histone methylation defines epigenetic asymmetry in the mouse zygote Arney KL, Bao S, Bannister AJ, Kouzarides T, Surani MA.

Int J Dev Biol. (2002) 46(3):317-20

The 2-cell block occurring during development of outbred mouse embryos is rescued by cytoplasmic factors present in inbred metaphase II oocytes Mario Zanoni, Silvia Garagna, Carlo A. Redi and Maurizio Zuccotti Int. J. Dev. Biol. (2009) 53: 129-134

DNA methylation state is preserved in the sperm-derived pronucleus of the pig zygote

Young-Sun Jeong, Seungeun Yeo, Jung-Sun Park, Deog-Bon Koo, Won-Kyung Chang, Kyung-Kwang Lee and Yong-Kook Kang

Int. J. Dev. Biol. (2007) 51: 707-714

Mammalian fertilization:the egg's multifunctional zona pellucida

Paul M. Wassarman and Eveline S. Litscher

Int. J. Dev. Biol. (2008) 52: 665-676

Epigenetic reprogramming of the genome-from the germ line to the embryo and back again

K L Arney, S Erhardt, R A Drewell and M A Surani

5 yr ISI Impact Factor $(2008)=3.271$

Int. J. Dev. Biol. (2001) 45: 533-540

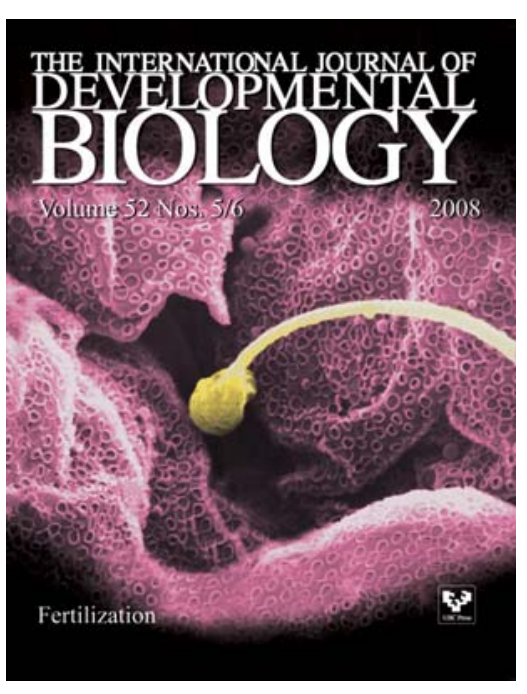

